\title{
Spectral Imaging and Clay Detection in Latgale Lakes
}

\author{
Rasma Tretjakova \\ Rezekne Academy of Technologies \\ Rezekne, Latvia \\ rasma.tretjakova@rta.lv
}

\author{
Sergejs Kodors \\ Rezekne Academy of Technologies \\ Rezekne, Latvia \\ sergejs.kodors@rta.lv
}

\author{
Juris Soms \\ Daugavpils University \\ Daugavpils, Latvia \\ juris.soms@du.lv
}

\begin{abstract}
- the survey of lake sediments is complex, time consuming and costly process with risks to human health. Additionally, manually obtained sediment samples provide incomplete data about a survey region. In turn, remote sensing methods are cost-effective and can provide continuous data about a survey region. Therefore, authors decided to perform a pilot experiment with a remote sensing method in order to detect clay sediments deposited in lakebeds. The evaluated method is the analysis of spectral images of Sentinel-2. Pearson coefficient and C4.5 datamining methods were applied for data analysis. Survey objects are Latgale lakes with and without clay sediments. The pilot experiment showed, that spectral imaging of lake water is not applicable method to detect definitely clay sediments in lakes, however, research results provide ideas about indirect methods, which must be studied in the future.
\end{abstract}

Keywords-clay, Latgale lakes, Sentinel-2, spectral imaging.

\section{INTRODUCTION}

Clay minerals (also referred to as phyllosilicate minerals) are crystalline aluminosilicate minerals organized in a layered structure. The crystal structure consists of two basic units: the $\mathrm{Si}$ tetrahedron, which is formed by a $\mathrm{Si}^{4+}$ ion surrounded by four $\mathrm{O}^{2-}$ ions in a tetrahedral configuration, and the $\mathrm{Al}$ octahedron, which formed by an $\mathrm{Al}^{3+}$ ion surrounded by four $\mathrm{O}^{2-}$ and two $\mathrm{OH}^{-}$ions in an octahedral configuration. These structural units are joined together into tetrahedral and octahedral sheets, respectively, by adjacent $S i$ tetrahedral sharing all three basal corners and by $A l$ octahedrons sharing edges. These sheets, in turn, form the clay mineral layer by sharing the optical $O$ of the tetrahedral sheet. Layer silicates are classified into eight groups according to layer type, layer charge, and type of interlayer cations. The layer type designated $1: 1$ is organized with one octahedral and one tetrahedral sheet, whereas the 2:1 layer type is organized with two octahedral and one tetrahedral sheet [1]. Clay is applied and used in a pharmacy and cosmetics, as well as in an environmental technology. Clay minerals can be used for the removal of organic pollutants from water. In order to remedy environmental damages caused by polluted gases clays and clay minerals can be used as adsorbents in natural form or after specific modification $[2]-[4]$.
The previously implemented research of the lake Plusons identified clay sediments [5], clay locations were found in lake Zeili as well. There are 2256 lakes in Latvia with the total area equal to $1001 \mathrm{~km}^{2}$, which stands for $1.5 \%$ of the territory of Latvia, that provides great scientific interest in terms of resource application in industry. However, the survey of lake sediments is complex, time consuming and costly process. Additionally, manually obtained sediment samples provide incomplete data about a survey region. Recently, it is common to apply geophysical methods like remote sensing to explore Earth resources. In turn, remote sensing methods are more costeffective and can provide continuous data about a survey region. The research goal is to evaluate the method of spectral analysis of satellite data in order to detect clay sediments in lake bottom.

\section{Material and Methods}

Analysing SIA "Geo Consultants" reports about sapropel search, the clay sediments are found in 109 of 199 lakes in Preili, Ludza and Rezekne regions. This data was applied to construct the dataset of samples. The constructed dataset contained 31 samples of Latgale lakes, from which 15 lakes contained clay sediments and $16-$ did not. The dataset did not contain all 199 lakes due to two reasons: firstly, lakes must be sufficiently large to be visible in Sentinel-2 image, secondly, it is pilot/ envision research. Considering the spectral features of water (the reflectance of water above $1150 \mathrm{~nm}$ is close to zero [6]), the bands $B 2-B 8$ are applicable and they have the minimal resolution of $20 \mathrm{~m} / \mathrm{px}$, which requires the minimal area of lake to be equal to $40 \times 40 \mathrm{~m}^{2}$ (0.16 ha) and water must be with no vegetation. And "the rule of 30 " is commonly applied to define the minimal amount of samples for a reliable statistical analysis.

The mean values of lake reflectance were calculated for each spectral band using Sentinel-2 multispectral image and SNAP software. Only the regions of water without vegetation were processed, that was achieved using the color-infrared (CIR) image to detect vegetation. The example of data is depicted in Fig.1.

The information about clay sediments of lake was coded using following system: if a lake contains clay sediments - code "one", otherwise - "zero". Using this

Print ISSN 1691-5402

Online ISSN 2256-070X

http://dx.doi.org/10.17770/etr2019vol1.4189

C 2019 Rasma Tretjakova, Sergejs Kodors, Juris Soms. Published by Rezekne Academy of Technologies.

This is an open access article under the Creative Commons Attribution 4.0 International License. 
encoding system, it was possible to measure Pearson correlation between the reflectance of band and the presence of clay sediments. Pearson correlation shows only direct relation between the one spectrum and the object. Therefore, the machine learning and classification algorithm $C 4.5$ was applied to detect the logical relations among the bands and the presence of clay sediments.

\section{Results AND Discussions}

Remote sensing methods detect objects analyzing their direct and indirect physical features. Spectral imaging was verified using Sentinel-2 images. The idea of spectral imaging application was based on the hypothesis about the correlation between the clay sediments and the chemical and microbiological content of lake water.

Spectral imaging, or imaging spectroscopy, combines the power of digital imaging and spectroscopy, providing a vastly improved ability to classify the objects in the scene based on their spectral properties [7]. Clay content and mineralogy have influence on the SWIR portion of the spectrum (1300-2500 nm), with the 2200 absorption feature being the characteristic of clays [1]. The topsoil mapping using satellites was previously studied and satellite multispectral sensors achieved results with the range of $R^{2}$ from 0.26 to 0.83 [8]. Landsat TM category belongs to the range of $R^{2}$ from 0.44 to 0.67 [8]. For example, the significant linear correlation between $M I D$-infrared index and topsoil clay content (\%) was experimentally proved in publication [9] showing that the $M I D$-infrared index over the driest bare soils allows separating sandy soils from clay. Bartholomeus et al. mention, that estimation of soil properties such as clay content is hampered, if the pixels have a vegetation cover over $20 \%$ and also if the pixels are covered by crop residues [10]. Garfagnoli et al. evaluated hyperspectral scanning with airborne platform for clay detection considering the illite and montmorillonite absorption feature at $2210 \mathrm{~nm}$, which is diagnostic indicator for these minerals [7].
The clay detection in the suspense of water is complicated mainly due to complex interactions of three optically detectable substances: algal chlorophyll, suspended sediments and dissolved organic substances. These substances have significant impact on the water quality. Each substance has its own reflectance and absorption trends complicating the derivation of the clay concentration estimation algorithms based on the remotely sensed data [6].

It is common to complete spectral reflectance measurements using a spectroradiometer in a laboratory before trying to detect Earth objects using multispectral satellites. The similar research structure can be found, for example, in the article [8]. If a clay presence influences the spectrum 1300-2500 nm of soil [1], the reflectance of water above $1150 \mathrm{~nm}$ is close to zero [6]. By analyzing the reflectance of water suspense with clay particles (Fig.2), Tuominen et al. found the best correlation between the amount of added clay and the band ratio R709 / R585 [6], that contradicts with the band ratio R595 / R754 proposed by Gin et al. [11], that Tuominen et al. explained by the different type or the particle size of the added clay in two independent researches.

At the same time, the source [12] provides the chart with water reflectance depending on its quality (Fig.3). The water with high or moderate sediment concentration (not exactly clay) has similar parameters as the water with added clay (Fig.2 and Fig.3). Therefore, hyperspectral analysis of water samples using portable spectrometer is realistic, however, the clay detection using satellite images is controversial. This was proved by the results of pilot experiment - the Pearson correlation of all bands are smaller than the moderate relation $(x<0.5)$. The algorithm $C 4.5$ provided the precision equal to $55.6 \%$, which is close to the probability of task to guess one value from two possible. The scatterplots of bands and clay sediments are depicted in Fig.4. The decision tree of C4.5 is depicted in Fig.5.

\begin{tabular}{|l|r|r|r|r|r|r|r|r|r|}
\hline & HasClay & \multicolumn{1}{|c|}{ B1 } & \multicolumn{1}{c|}{ B2 } & \multicolumn{1}{c|}{ B3 } & \multicolumn{1}{c|}{ B4 } & \multicolumn{1}{c|}{ B5 } & \multicolumn{1}{c|}{ B6 } & \multicolumn{1}{c|}{ B7 } & B8 \\
\hline Razna & 1 & 0.0169 & 0.0148 & 0.0148 & 0.0078 & 0.0074 & 0.0089 & 0.0094 & 0.0082 \\
\hline Sorockas & 0 & 0.0173 & 0.0139 & 0.0134 & 0.0114 & 0.013 & 0.0165 & 0.0186 & 0.0175 \\
\hline Vertuksnas & 0 & 0.0174 & 0.0129 & 0.0149 & 0.012 & 0.012 & 0.0105 & 0.0113 & 0.0113 \\
\hline Veveru & 1 & 0.0176 & 0.014 & 0.0174 & 0.0126 & 0.0131 & 0.0136 & 0.0154 & 0.0158 \\
\hline Tiskadu & 0 & 0.0207 & 0.018 & 0.0256 & 0.0196 & 0.0177 & 0.0095 & 0.0102 & 0.009 \\
\hline Skenovas & 1 & 0.0126 & 0.011 & 0.0135 & 0.012 & 0.0127 & 0.0122 & 0.015 & 0.0148 \\
\hline Paugulu & 1 & 0.0139 & 0.0122 & 0.0132 & 0.0123 & 0.0112 & 0.0087 & 0.0107 & 0.0101 \\
\hline Vecanu & 1 & 0.0121 & 0.0102 & 0.0104 & 0.0099 & 0.0107 & 0.0112 & 0.0132 & 0.0126 \\
\hline
\end{tabular}

Fig. 1. Reflectance of lake water and data about clay sediments

Considering the Fig.2 and Fig.3, clay added to water does not provide specific change of reflectance, that corresponds to the low Pearson correlation of all bands (Fig.4). The constructed decision tree uses the condition " $B 2>0.01$ " as the main feature for recognition (Fig.5), where $B 3$ is equal to $490 \mathrm{~nm}$ wavelength. According to the Fig. 4, $B 3$ is the spectral band, where clear water decreases its reflectance, but water with sediments increases its reflectance. $B 6(740 \mathrm{~nm})$ is point, where the reflectance of clear water is close to zero, but water with added clay has strong reflectance decrease. $B 6$ is close to bands found by Tuominen and Gin (709 nm and $754 \mathrm{~nm}$ respectively).
Therefore the range $700-800 \mathrm{~nm}$ is important for clay detection, but detection bands are specific for each water body. The subject of Tuominen's research was coastline water, where sediments are continually mixed with water, but a clay must sink to the bottom in static water. So, the category "water with sediments" of Fig.3 is the more correct description to the range 700-800 nm. Algorithm C4.5 has tried to identify the reflectance ranges of bands to complete classification, however, the usage of ranges is controversial too, because satellite images have errors caused by atmospheric effects and the values of pixels are averaged due to an image resolution. Additionally, 
Tuominen mentions many factors, which can influence water spectral characteristics [6].

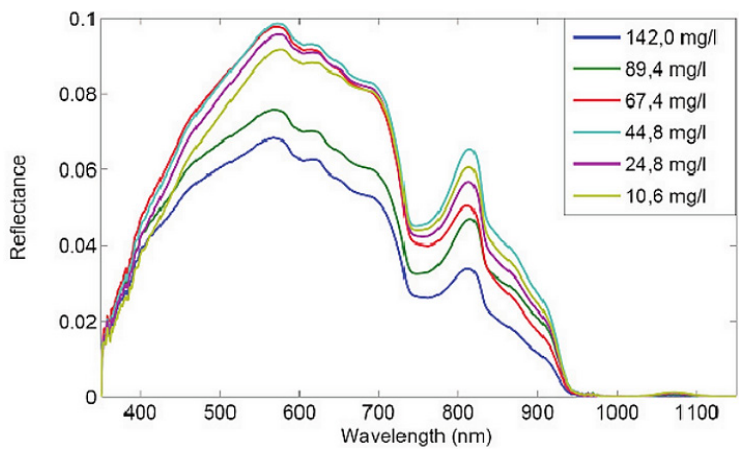

Fig. 2. Reflectance spectra of water samples containing varying amounts of added clay [6]

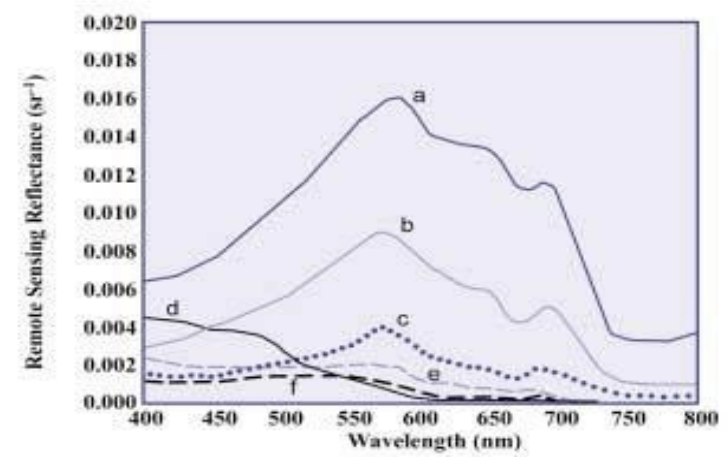

Fig. 3. (a) waters with very high sediment and gelbstoff concentrations, (b) high sediment and gelbstoff concentrations, (c) moderate sediment and gelbstoff with some phytoplankton,

(d) clear water, (e) waters with moderate chlorophyll and sediment concentrations, (f) waters with moderate chlorophyll concentration [12]

\section{Conclusions}

The literature analysis identified, that spectral imaging of lake water is not useful to detect clay sediments in lake bottom. That is proved by two facts: firstly, clay particles sink to the bottom in static water, secondly, shape of spectral reflectance of clay suspension is similar to suspension with other sediment particles. The completed pilot experiment provided a similar conclusion. However, it does not contradict with Tuominen et al. [6] and Gin et. al [11] results, who studied suspended clay of coastline using field spectrometer.

Further research can include studies of indirect indicators, for example, - phytoplankton. Due to their turbidity the clay particles due reduce Solar energy available to the grazers or bacteria, but they may, however, contain nutrients and trace-elements that can be utilised by phytoplankton or bacteria [13]. In lakes, the clay-related turbidity has shown to have serious effects on the food web and an ability to prevent the improvement of the lake condition due to the restoration methods [14].

If clay sediments are related with the retreat of glaciers and common to glacier lakes, the geospatial analysis can be applied to detect geospatial relations among cleyey lakes.

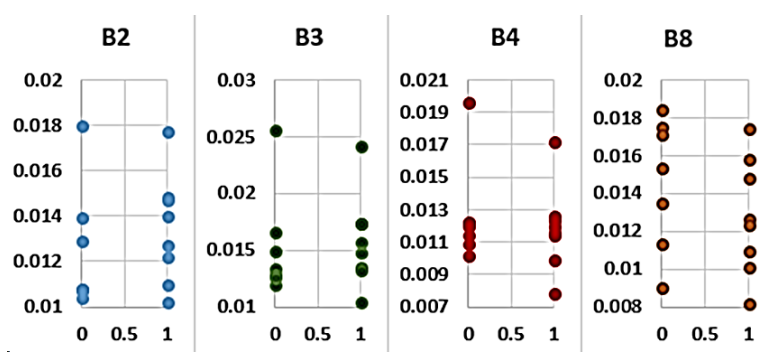

Fig. 4. Scatterplots of $R G B$ and NIR bands, where points are clustered by the presence of clay sediments"

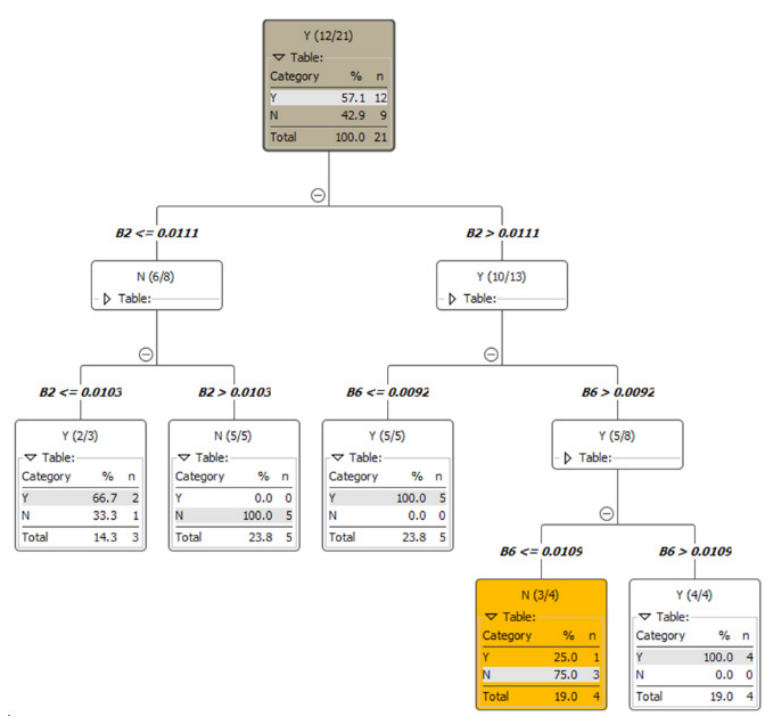

Fig. 5. Decision tree constructed by $C 4.5$

\section{REFERENCES}

[1] E. Ben-Dor, "Quantitative remote sensing of soil properties," Advances in Agronomy, vol. 75, pp. 173-243, 2002. https://doi. org/10.1016/S0065-2113(02)75005-0

[2] D. Zadaka, Y.G. Mishael, T. Polubesova, C. Serban and S. Nir, "Modified silicates and porous glass as adsorbents for removal of organic pollutants from water and comparison with activated carbons," Applied Clay Science, vol. 36, pp. 174-181, 2007. https:// doi.org/10.1016/j.clay.2006.04.012

[3] E. Szabó, K. Vajda, G. Veréb, A. Dombi, K. Mogyorósi, I. Ábrahám and M. Májer, "Removal of organic pollutants in model water and thermal wastewater using clay minerals," Environ Sci Health A Tox Hazard Subst Environ Eng., vol. 46, no.12, pp. 1346-1356, 2011. https://doi.org/10.1080/10934529.2011.606679

[4] C. Volzone, "Retention of pollutant gases: comparison between clay minerals and their modified products," Applied Clay Science, vol. 36, pp. 191-196, 2007. https://doi.org/10.1016/j.clay.2006.06.013

[5] R. Tretjakova, S. M. Misina and J. Lukašenoks, "Chemical and Biological Properties of the Lake Blue Clay,” Environment. Technology. Resources, Proceedings of the 11th International Scientific and Practical Conference. vol. I, pp. 290-295, 2017. http:// dx.doi.org/10.17770/etr2017vol1.2635

[6] J. Tuominen, T. Lipping, V. Kuosmanen and S. Repka, "HYPERSPECTRAL DETECTION OF MARINE CLAY IN COASTAL WATERS USING THE SPECTRAL ANGLE METHOD," EARSeL eProceedings, vol. 9, no. 2, pp. 31-41, 2010.

[7] F. Garfagnoli, A. Ciampalini, S. Moretti and L. Chiarantini, "DETECTING CLAY MINERALS IN SOILS THROUGH HYPERSPECTRAL REMOTE SENSING," 4th EARSeL Workshop on Remote Sensing and Geology, Mykonos, Greece, 24st - 25th May, pp. 95-101, 2012.

[8] C. Fongaro, J. Demattê, R. Rizzo, J. Lucas Safanelli, W. Mendes, A. Dotto, L. Vicente, M. Franceschini, and S. Ustin, "Improvement of Clay and Sand Quantification Based on a Novel Approach with a Focus on Multispectral Satellite Images," Remote Sensing, vol. 10, no. 10, p. 1555, Sep. 2018. https://doi.org/10.3390/ $\underline{\text { rs10101555 }}$ 
[9] M. Shabou, B. Mougenot, Z. Chabaane, C. Walter, G. Boulet, N. Aissa, and M. Zribi, "Soil Clay Content Mapping Using a Time Series of Landsat TM Data in Semi-Arid Lands," Remote Sensing, vol. 7, no. 5, pp. 6059-6078, May 2015. https://doi.org/10.3390/ $\underline{\text { rs70506059 }}$

[10] H. Bartholomeus, G. Epema and M.Schaepman, "Determining iron content in Mediterranean soils in partly vegetated areas, using spectral reflectance and imaging spectroscopy," Appl. Earth. Obs. Geoinform, vol. 9, no. 2, pp. 194-203, 2007. https://doi. org/10.1016/j.jag.2006.09.001

[11] K.Y.-H. Gin, S. T. Koh and I.-I. Lin, "Spectral irradiance profiles of suspended marine clay for the estimation of suspended sediment concentration in tropical waters," International Journal of Remote Sensing, vol. 24, no. 16, pp. 3235-3245, 2003. https://doi.org/10.1080/01431160110114934

[12] Reports of the International Ocean-Colour Coordinating Group,
"Remote Sensing of Ocean Colour in Coastal, and Other Optically-Complex, Waters," IOCCG Report Number 3, 2000.

[13] J. Niemistö, H. Holmroos, Z. Pekcan-Hekim and J. Horppila, "Interactions between sediment resuspension and sediment quality decrease the TN:TP ratio in a shallow lake," Limnology and Oceanography, vol. 53, pp. 2407-2415, Nov. 2008. https://doi. org/10.4319/10.2008.53.6.2407

[14] J. Horppila, A. Liljendahl-Nurminen, "Clay-turbid interactions may not cascade - a reminder for lake managers," Restoration Ecology, vol. 13, pp. 242-246, May 2005. https://doi.org/10.1111/j.1526-100X.2005.00031.x

\section{ACKNOWLEDGEMENTS}

European Regional Development Fund Postdoctoral research aid Nr.1.1.1.2/16/I/001 research application "Identification of blue clay in lakes of Latgale region and possibilities of its application, Nr.1.1.1.2/VIAA/1/16/131".
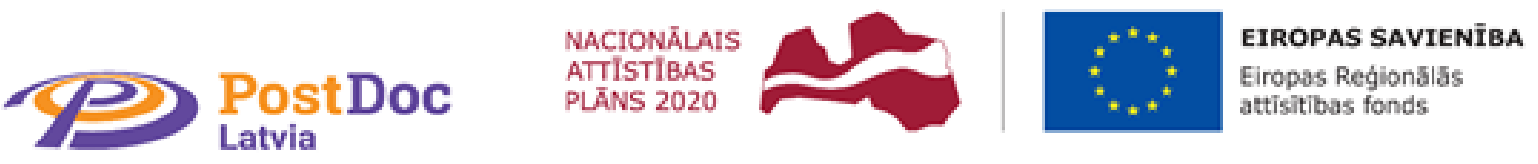

IEG ULD I J U M S TA $V \bar{A} N \bar{A} K O T N \bar{E}$ 